\title{
An Investigation of the Development of a Reflective Virtual Learning Community in an Ill-Structured Domain of Instructional Design
}

\author{
Victor Law \\ Department of Educational Psychology \\ Jeannine Rainbolt College of Education \\ University of Oklahoma, USA \\ E-mail: vlaw@ou.edu
}

Xun $\mathrm{Ge}^{*}$

Department of Educational Psychology

Jeannine Rainbolt College of Education

University of Oklahoma, USA

E-mail:xge@ou.edu

\section{Deniz Eseryel}

Department of Educational Psychology Jeannine Rainbolt College of Education

University of Oklahoma, USA

E-mail: eseryel@ou.edu

*Corresponding author

\begin{abstract}
This article examines the development of novice instructional designers in a reflective learning community. The study was situated in a blended learning course, which utilized a web-based learning management system as a communication platform. Drawing from communities of practice as a theoretical framework, we examined (1) how individual and group characteristics influenced knowledge construction, (2) how members developed their epistemic frames of instructional design, and (3) the dynamics of group interactions during the knowledge constructions in the learning community. The findings highlighted issues related to the development of an online learning community, such as considering prior members' knowledge and experience towards learning in a technology-mediated environment, enculturating minority groups in the learning community, providing structure to promote the formation and development of a learning community, and cultivating shared leadership behaviors.
\end{abstract}

Keywords: Virtual Learning Community; Ill-Structured Knowledge Domain; Instructional Design; Individual and Collective Characteristics; Scaffolding; Epistemic Frames; Emergent Leadership

Biographical notes: Mr. Victor Law is a PhD Candidate with the Department of Educational Psychology at the University of Oklahoma. His research interests include computer-supported collaborative learning, self-regulation, ill- 
structured problem-solving, scaffolding, and game-based learning.

Dr. Xun Ge is an Associate Professor with the Program of Instructional Psychology and Technology, Department of Educational Psychology at the University of Oklahoma. Her research interest includes virtual learning communities, computer-supported collaborative learning, and designing learning technologies and open learning environments to support students' illstructured problem solving and self-regulated learning.

Dr. Deniz Eseryel is an Assistant Professor at the Instructional Psychology and Technology Program of the University of Oklahoma. Her research focuses on investigating the nature of expertise in complex knowledge domains, and on developing new instructional approaches, technologies, and assessment methods to support higher-order learning outcomes such as complex, illstructured problem solving.

\section{Introduction}

In this digital age, we are surrounded by emerging technologies updating on daily basis. These technologies have afforded us with lots of wonderful opportunities and possibilities, one of them being the use of technology platforms to support collaboration and building of virtual learning communities for formal or informal learning in various contexts. A myriad of literature supports the importance of communities (physical or virtual) in knowledge building to learners of all ages. On the premise of socio-cultural theory represented by Vygotsky (1978), social interactions are an integral part of learning. Community participation promotes the advancement of collective knowledge and supports the growth of individual knowledge (Scardamalia \& Bereiter, 1994). In addition, it is argued that this information-rich society requires people to interact with and learn from people from diverse background, which further justifies the benefits of community of learners and community of practice (Barab \& Duffy, 2000; Wenger, 1997).

The argument that community participation leads to knowledge advancement is justified by the assumption that members will interact with each other, and they will find and acquire mental models and have the opportunity themselves to be models and apprentices (Renninger \& Shumar, 2002). From the perspective of cognitive psychology, when learners participate in a community, peers will interact with each other by sharing information, asking questions, providing feedback, receiving explanations, negotiating meanings, resolving conflicts, and co-constructing knowledge (Webb \& Palincsar, 1996). Therefore, a learning community provides affordances for learners to share their expertise with each other and allows them to see multiple perspectives (Brown \& Campione, 1994), which is an important aspect of problem representation in solving complex, ill-structured problems (Feltovich, Spiro, Coulson, \& Feltovich 1996). The learning community can facilitate individuals' cognitive and metacognitive development.

However, in practice there is a lack of understanding of specific interaction processes in virtual learning communities, particularly insufficient data to explain members' motivation for participating in virtual learning communities and factors leading to successful or unsuccessful community building, particularly in the context of complex, ill-structured problem solving in an ill-structured domain. While members of a community share many common characteristics, there exist different individual characteristics. This study was concerned with how individual characteristics are related to group characteristics, how the interaction of the two types of characteristics contributes 
to individuals' knowledge construction and groups' knowledge building, and how we can create an environment conducive to supporting community development and individuals' skill development in an ill-structured domain such as instructional design (ID).

Therefore, this article reports a case study that investigated the influence of the interaction between individual characteristics and group characteristics on community participation and knowledge building. In addition, we examine the effects of scaffolding mechanisms aiming at deepening graduate students' understanding of instructional design and developing their ID skills through peer interaction and community support. This study was built on the theoretical framework that community of learners and practice not only supports the development of learners' knowledge and skills, but also the development of their professional identity.

\section{Nurturing a Learning Community of Instructional Design Professionals}

Instructional design is a field of study concerned with designing learning environments that promote the acquisition of desired learning outcomes for any targeted population. The work of an instructional design practitioner involves designing the most effective and efficient learning environment for target learners to acquire the desired learning outcomes. The design blueprint produced by the instructional designer can be likened to a blueprint of a house designed by an architect. This design blueprint is not just a schematic drawing of the final product; rather, it is a detailed plan of action, scheme, program, or method worked out beforehand for the accomplishment of an objective.

Instructional design is a complex and ill-structured problem-solving activity (e.g., Goel \& Pirolli, 1989; Greeno, Korpi, Jackson, \& Michalchik, 1990; Perez, Johnson, \& Emery, 1995), in which (1) there are too many factors influencing the problem situation; (2) these factors exhibit dynamic interrelationships that may not always be transparent to the designer; (3) there is no one correct solution to any given design problem. Instructional design problems are generally situated in and emergent from a specific context. In most cases, the designer is constrained by circumstances, e.g., one or more aspects of the problem situation may not be well-specified, the problem description may not be clear or well-defined, or all the information required to solve the problem may not be provided. In most design problems, there are a variety of solution approaches, each of which may work as well as any other. Yet, without empirical proof, instructional designers are often required to make judgments about the situation and prescribe the most effective and efficient solution based on them.

When a knowledge domain is complex and ill-structured, like instructional design, an important aspect of instructional design education should involve helping novices develop the cognitive flexibility (Feltovich, Spiro, Coulson, \& Feltovich, 1996) so that they will be able to view a given design problem from multiple angles, see possible design solutions, settle on a solution depending on the context of the problem, and be able to defend their solution. In order to foster such a learning environment, learning communities are especially promising given the existing research on cognitive flexibility (Spiro, Coulson, Feltovich, \& Anderson, 1988) and communities of practice (e.g., Lave \& Wenger, 1991). 


\subsection{Instructional Design Learning Community}

Like other communities of practice, instructional designers constitute a group of people who have defined a vast set of collective knowledge while - and as a result of - working together over time. The structure and grammar of instructional design learning community includes the following elements, which are called epistemic frames by Shaffer (2006):

- Skills: the abilities and competencies that community members are able to perform and demonstrate

- Knowledge: the facts and information shared by community members

- Identity: the social and cultural roles assumed by community members

- Values: the opinions and beliefs held by community members that define what is important (and conversely, not important)

- Epistemology: the justifications and methods of proof that legitimize actions and claims within the community

The shared repertoire of knowledge is continuously developed and refined through the engagement of multiple community members in a joint enterprise, such as working together to solve complex design problems. By forging linkages between the individual frame elements over time, professionals develop more expertise in their field and become more efficient and effective in their overall practice. When new members enter a profession, it is unlikely that they have a full grasp of each of the different frame elements or, for that matter, the connections among the frame elements. However, as the new members grow and learn in the ways of the profession, their understanding of the individual frame elements - and the relationships among them - will increase, resulting in an increasingly more sophisticated epistemic frame. To connect this to Lave and Wenger's work (1991), new members who are at the periphery of a community of practice would have underdeveloped and loosely-linked frame elements in their epistemic frame, while expert members of the community in full participation would have welldefined epistemic frames with dense connections between and among the different frame elements.

\subsection{Instructional Design Learning Community as a Reflective Setting}

Nurturing newcomers into the field of instructional design requires a reflective setting, where novice members engage in authentic activity in the presence of a mentor and a support structure of peers, as a mechanism for the development of professional identity. Particularly relevant to the domain of design education is the work of Schön (1987), which examines a particular type of practicum - a reflective practicum, where novice professionals engage in authentic, messy, and ill-structured problems under the supervision of more experienced mentors. As a result of undergoing the reflective practicum experience, novice professionals generally mature in their ways of thinking, doing, and acting, thus making significant progress towards becoming reflective practitioners who exhibit artistry within their field. Schön identifies this type of expertise as reflection-in-action: the ability to shift from standard, skilled performance to a more analytical and experimental mode when an unexpected complication arises during practice. As the expert designer reflects-in-action, she engages in on-the-spot thought and action experiments, positing a potential action, and considering its consequences on her design and how those repercussions might affect future moves. 
The affordances of virtual learning communities provide ideal settings to support nurturing novice professionals to be reflective practitioners, facilitating their immersion in the norms, rituals, discourse, and culture of practice (Schön, 1987) while supporting their expertise development. Creating an instructional design virtual community with the outcomes of an epistemic frame requires an intimate understanding of the reflective participant structures. The community allows the students to brainstorm ideas, identify constraints, research existing design theories and models, build prototypes, and evaluate their designs in order to understand the nuances of instructional design process. They meet regularly with their fellow students and professors to provide updates, share suggestions, and get feedback, thus experiencing the collaborative nature of the profession. They write reports, give oral presentations, and participate in formal design reviews to develop the communications skills essential for success. These activities come together to form powerful and authentic experiences, through which instructional design novices begin to develop a deeper understanding of what it means to be an instructional designer.

\section{The Present Study}

Given the numerous advantages of a virtual learning community for the development of professional identity and expertise, we built a structured online learning environment to encourage students' engagement in the learning community and promote a reflective setting. It was expected that learners would participate actively in the virtual learning community to share information, construct knowledge, and develop expertise. However, there is little empirical evidence to support this assumption. Most of the past research on learners' online interactions either focused on the quantity of members' contribution (Dennen, 2005) or the factors influencing members' contributions (e.g., Cheung, Hew, \& $\mathrm{Ng}$, 2008; Xie \& Ke, 2009) instead of examining how learners interacted in or contributed to the virtual learning community.

Although the previous works provided us with insights into learners' participation and interaction in a virtual learning community, we were still left wondering how, if any, different factors may influence knowledge construction and knowledge building in a virtual learning community, especially in the context of complex and ill-structured knowledge domains. The previous studies (e.g. Cheung, Hew, \& Ng, 2008; Dennen, 2005) mainly focused on group collaboration in the class context instead of building a learning community and developing professional identity. We did not have sufficient empirical data on the actual knowledge construction and knowledge building processes as the community develops over time. Framed in a virtual learning community, this study was intended to explore the interactive processes and patterns as the learning community developed over time, and the influence of the instructional strategies on the building and development of individual identity and learning community. Additionally, we also tried to examine how individual characteristics and group characteristics shaped the learning community over time.

\subsection{Purpose of the Study}

The purpose of this study was to build on previous studies and identify the main factors contributing to a virtual learning community, particularly in the context of a course on instructional design, which is an archetypal example of a complex and ill-structured knowledge domain. In addition, we intended to understand how members participated in structured and guided online discussions, how they interacted with each other, and how 
individual characteristics and group characteristics influenced members' knowledge construction and building. Three research questions guided this study:

Question 1: How do individual characteristics contribute to the group characteristics that influence knowledge construction process in a reflective virtual learning community setting?

Question 2: How effective were the strategies used to facilitate participants' reflective interaction processes in supporting the development of epistemic frames of instructional design learning community?

Question 3: What are the dynamics of group interaction that support collective knowledge construction process in an ID learning community?

\section{Method}

We employed a multiple-case design to examine the process of learning ID skills in a virtual community (Creswell, 2007; Yin, 2008). Multiple case study design allowed us to explore the issues of knowledge construction in a virtual learning community within a bounded system (Creswell, 2007) - an ID course offered in a blended format. To understand the phenomenon, we examined multiple individuals in the learning community using multiple sources of information, such as observations, interviews, and online discussion logs, in order to identify case-based themes (Creswell 2007).

Table 1. Demographics Characteristics of the Interviewees

\begin{tabular}{|l|l|l|l|}
\hline Name & Age & Ethnicity & Life Experience \\
\hline Zoe & 20 's & Hispanic & $\begin{array}{l}\text { She was an international student, who came to the US } \\
\text { two semesters ago. She was an elementary school } \\
\text { teacher before she came to the US. }\end{array}$ \\
\hline Ella & 20 's & Caucasian & $\begin{array}{l}\text { She just finished her Bachelor degree in psychology. } \\
\text { This was her first semester in the graduate college. }\end{array}$ \\
\hline Amber & 20 's & Asian & $\begin{array}{l}\text { She was another international student. This was her } \\
\text { second semester in the master program. }\end{array}$ \\
\hline Janet & 20 's & Asian & $\begin{array}{l}\text { She just finished her Bachelor degree in English, and she } \\
\text { came to the US for graduate school. }\end{array}$ \\
\hline Eva & 40 's & $\begin{array}{l}\text { Multi- } \\
\text { ethnicity }\end{array}$ & $\begin{array}{l}\text { She was an instructional designer at a community } \\
\text { college. She was responsible for developing online } \\
\text { courses and managing an online learning management } \\
\text { system for the college. } \\
\text { years. She was a student returning to school after being } \\
\text { away from school for 10 years. }\end{array}$ \\
\hline Luke & 20 's & Caucasian & $\begin{array}{l}\text { He just graduated from college. This was his first } \\
\text { semester in the master program. He also taught an } \\
\text { undergraduate class. }\end{array}$ \\
\hline
\end{tabular}




\subsection{Participants}

Sixteen students from a graduate-level introductory instructional design class participated in this study. Among the sixteen participants, ten of them were in their 20s, and five of them were international students. Although none of them had formal instructional design training, six participants held jobs as instructional designers or teachers. Purposeful sampling was employed to recruit seven interviewees, who represented a range of ethnicity, age, and life experiences, to capture the richness of experience by different participants. Their individual characteristics are displayed in Table 1.

\subsection{Context}

The class was situated in blended graduate-level instructional design course, which met face-to-face every Monday for three hours. The in-class activities included lecture, small group discussions and other activities. Beyond the face-to-face meetings, the class was extended by online discussions. Students were engaged in online discussions by following a three-step protocol, which required students to (a) post a response to the guiding questions provided by the instructor, (b) respond to peers' initial posts as well as peers' comments to their initial posts, and (c) post a reflective summary of their discussion experience.

In addition to the discussion protocol, the instructor used different strategies to scaffold the online discussions, such as dividing the class into smaller groups, and guiding students' discussions with questions. The protocol required the students to post their thoughts and respond to at least one student by Sunday midnight (e.g., 11:59 PM). Guiding questions were given after the face-to-face meeting to facilitate students' discussion. Some examples of the guiding questions are listed below:

- Pick two items from the following concept list, briefly discuss the relationship between or among each of the list. Illustrate the relationship by providing an example (post to forum)

$\begin{array}{cc}\circ & \text { Norm referenced assessment vs. criterion referenced } \\ & \text { assessment } \\ \circ & \text { Validity, Reliability, and practicality } \\ \circ & \text { Formative evaluation vs. summative evaluation } \\ \circ & \text { Confirmative evaluation } \\ \circ & \text { Performance test vs. objective test } \\ \circ & \text { Absolute standards vs. relative standards }\end{array}$

- What are the relationships between the three concepts (i.e., learning theories, instructional theory, and instructional design models)? If possible, create a figure to illustrate the relationships.

- If you have already worked as an instructional designer (formal or intern; or on a similar job), please share what your role is AND should be. If you have not worked as an instructional designer, please share your thoughts about what the role of an instructional designer should be based on your understanding. 


\subsection{Data Sources and Analysis}

We collected multiple sources of data, including observations, semi-structured interviews, and all the online discussion logs. One researcher observed three class meetings during the semester. Seven semi-structured interviews, taking about 35-45 minutes each, were conducted at the end of the semester. The interviews focused on students' learning experiences, including both in-class and online learning experiences, and their perceptions of their own ID skill development. Some examples of the interview questions were: "What is your general experience during online discussion", "Do you think the guiding questions for active readings are useful? How and why?", "How much time have you spent in online discussion each week?" Online discussion messages were captured to understand students' online interactions. The discussion messages not only recorded the content of the discussion, but also showed the timestamp of each message, and which messages students responded to. In addition, Desire2Learn (D2L), a learning management system maintained all the statistics of students' online activities, such as the number of messages each student read.

Open coding technique was employed to code the interviews (Shank, 2002). Interviews were transcribed and then read to identify patterns. Subsequently, the researchers searched for variables by counting and clustering the codes that had been found. The data were then displayed to compare and contrast different cases, examine outliers, and identify themes. Possible factors were identified that affected members' interactions and knowledge construction in the learning community. Finally, we triangulated the findings with the descriptive statistics of the online discussions (e.g. the number of postings of each members and the number of messages read), the content in the online discussion logs, and observation data during in class discussions.

\section{Results}

\subsection{Question 1. How do individual characteristics contribute to the group characteristics that influence knowledge construction process in a reflective virtual learning community setting?}

In examining the virtual learning community, we found that the individuals brought with them rich assets to this learning community, such as their unique past experiences, prior knowledge, and self-perceptions, which contributed to the knowledge pool of the community and facilitated the knowledge construction process of the community. At the same time, the diverse characteristics of the group, with its collective experience and knowledge, also enriched the individual experience and benefited the community as the members participated in the professional activity of ID. In the following section, we further elaborate how individual characteristics contribute to group characteristics that influence knowledge construction process in a reflective virtual learning community setting.

\subsubsection{Individual Prior Knowledge and Self-perception of Electronic Communication}

In a virtual learning community, members communicate via computer-mediated media. Therefore, their prior experience and their perception of the communication media may influence how they interact with their peers, which, in turn, affect their learning. In this class, some of the more mature members voiced concerns towards the use of discussion 
forum. Eva was new to the concept of virtual learning community, and she viewed learning with peers as an information acquisition process. Eva said, "It [D2L] is new. I do not have D2L in my previous student life...I think I tend to learn a lot more in class. I think the medium of instruction that I truly believe is still classroom instructor-led." Hence, instead of building knowledge with the peers in the virtual community, she expected to get information from the online discussion. When her peers could not give her the information that she wanted, she felt disappointed and frustrated. Eva's perception and behaviors agreed with the results found in a previous study that students did not feel that they came together in a virtual environment to learn (Thomas, 2002).

In contrast, many younger members, who were in their twenties and more familiar with online discussion, felt that they learned a lot from the discussion forum. Grace and Zoe would go to the discussion forum to ask for help when they faced difficulties in understanding a concept or when they were stuck in their projects. Luke enjoyed seeing fellow members' perspectives. The D2L log showed that younger members logged on to D2L more frequently than the older members. This result might be due to their possible prior knowledge and perception of the electronic media.

Although online discussion might promote an individualist model of learning for some students (Thomas, 2002), especially for the older generation, online discussion could be an effective interactive mode of learning. The older generation might feel isolated in the virtual community, but the newer generation, who had been used to computer-mediated communication, such as MSN and Facebook, probably felt that the online communication was part of their life. Hence, they naturally shared and learned in the virtual learning community.

\subsubsection{Collective Prior Knowledge}

Individual prior knowledge can affect individual experience and knowledge building in a learning community, but the collective prior knowledge allows individuals to learn from each other. We illustrate how the collective prior knowledge contributed to community understanding of the issues regarding learning assessments, including topics like different types of assessments, validity and reliability of assessments, and different types of standards. During the online discussion, many members contributed their own experiences related to this topic, which led to a fruitful discussion. Luke explained how he assessed his students in a class that he taught: he allowed his students to revise and resubmit their homework to get better grades. Joseph argued about the consequential validity, which Luke and Joseph learned in a measurement class, of Luke's assessment. Their shared understanding of the assessment issues allowed them to reflect and develop a deep understanding of the topic.

While the shared experience among the members could facilitate their discussion, their unique working and cultural experience enriched the discussion and provided a boarder understanding of assessment to the whole learning community. Our members enriched the learning community by bringing in industry and international experience. Anna had been working in the industry for years. She brought in the issues of practicality in assessments in the discussion. Besides reliability and validity, she suggested that time, cost, and location should be considered in the decision-making process for assessments. This kind of practical concerns was important in many professional contexts, but not highlighted in the course materials. Another student, Janet, had been an occupational therapist for many years. She provided some policy guidelines and actual assessment examples for assessing special education students. Indeed, understanding the needs of 
special education students could be a very important for the participants who would work in the US K-12 environment, which had many students with special needs. Zoe was a pre-school teacher from South America, and she explained how assessment was conducted in her home country, which was quite different from how assessment was conducted in the US. In conclusion, we observed that members brought in their prior knowledge and experience that allowed the entire community to reflect on different issues regarding different topics.

\subsubsection{Special Characteristics of International Students}

International students not only brought in benefit but also challenges to a virtual learning community. On one hand, they enriched the learning community with their cultural experiences. On the other hand, their limited English skills might hinder their participation in the community, which might negatively affect the whole community.

In the learning community, we had five non-native English speaking members who were relatively new to the United States. In addition, we had two members whose first languages were not English, but they had been in the United States for many years. Although the international students did not contribute as many messages as the domestic students did, they enriched the discussions by bringing in their cultural perspectives. For instance, Zoe shared her experience about the educational system in her home country, which helped the domestic students to understand how assessment was being conducted in another country. Ella's project was about teaching advanced placement psychology to domestic high school students, and the comment from an international student prompted her to explain the term "advanced placement psychology" in her design document.

Because of language difficulties, members whose first language was not English found it difficult to contribute and participate in the virtual learning community. Grace said, "It's my first semester as an international student. I have a lot of difficulties in reading and writing compared with the native speakers." Zoe also found that participating in the learning community was very time consuming because of her language barriers. She said, "it takes me a long time to write my summaries and my discussions ... Sometimes, I write it in Spanish and then I translated it." Because of the heavy workload of the class, English language learners might be less motivated to contribute in the virtual community when they found it difficult to write. The language issues of international members might explain why the five international members in the learning community of 16 members only contributed to $22 \%$ of the postings.

Although international students did not contribute as many messages as domestic students did, some of them participated in the forum by reading other messages. We found some peripheral participation from some of the international students, which was consistent with other studies that international students participated in online and blended courses by reading others' postings (Wise, Speer, Hsiao \& Marbouti, 2011). The logs showed that over the semester more than eleven hundred messages were posted, and two international students read most of the messages. In addition, although those two students posted relatively few messages, they increased their contribution to the community towards the end of the semester. It was probably due to the fact that their confidence and competence in participating in the learning community grew over time as they felt more comfortable with their English and the US educational system.

Although language barriers could hinder the number of messages contributed by international students, the quality of their contributions was very good in general. Instead of writing long messages, they were able to use other means to present and share their 
ideas. Zoe was known in the learning community for her ability to communicate complex ideas using charts and graphics, and her peers were impressed by her visual representation skills. On the tenth week, the members were required to synthesize different concepts of instructional design. Ian used a drawing of a pot of flower to present his understanding of complicated concepts, which generated great discussions within the learning community. Therefore, it can be beneficial to a learning community when international students are encouraged to express themselves in ways other than text.

Not only could international students provide different perspectives to the domestic students, they could also be a natural support group for each other. In the class, members were required to get feedback on their projects. Although it could be time consuming for the international students to read others' messages and then to provide feedback, Zoe gladly gave feedback to her fellow international students. She said, "I am an international student, and I try to support them because I know how difficult for us to write." Grace said, "Actually, I have a very close relationship with the classmates ... I can talk to them directly. Actually, Amber [another international student] and I, usually communicate via MSN about the assignments and classwork."

\subsection{Question 2. How effective were the strategies used to facilitate participants' reflective interaction processes in supporting the development of epistemic frames of instructional design learning community?}

The instructor of the class utilized different strategies to scaffold learning community members' epistemic frames of instructional design (i.e., ID skills and knowledge, selfreflection skills and so on). These strategies included providing a protocol for online discussion to encourage reflective discourse, grouping members in small diverse groups to keep the online discussion more manageable, and providing guiding questions to start the conversation and focus members' attention on major issues. Our findings suggested that these strategies were generally successful in facilitating members' participation and development of epistemic frame. However, there were some interesting findings. We elaborate on these in the following sections.

\subsubsection{A Protocol for Online Discussion}

In a learning community, it is important to encourage members to engage in a reflective discourse among themselves, so that members can scaffold each other in their learning. Therefore, the instructor established a protocol to motivate participation in the learning community. The protocol required members to (1) post one initial reaction towards the weekly readings, (2) interact with at least one member in the online discussion forum, and (3) post a reflection to synthesize what they had learned from the readings and discussion. We found that the protocol guided members' behaviors in the online discussion, that, in general, they posted and read a lot of messages. Nevertheless, a few members treated the protocol like a checklist, and did not really immerse in the community. Some students also found the protocol, especially the deadline for posting, negatively affecting their participation in the community.

First, we found that many members actively participated in our learning community by posting messages and reading others' comments. In fact, many of them participated in the forum discussion above and beyond the requirement of the protocol. Instead of interacting with one member per week, they interacted with multiple members 
every week. During the interviews, many members expressed that they enjoyed participating in the discussion, and they learned new skills and knowledge from others.

Members not only engaged in the reflective discourse by posting messages, they also engaged in learning by reading others' messages. Members read and reflected on other's postings. Seven members read more than half of the 1120 messages. Among those seven, four of them read more than 1000 messages over the semesters. Members also spent a lot of time in the virtual community. On the average, the members spent between three to seven hours just in the discussion forum. The members had a heavy workload in this class, including readings, discussion forum, and design projects. Many of them were working full time, and a few of them were living far away from the campus. The dedication of the members to the participation of the forum suggested that they were intrinsically motivated to join the community. Luke said, "it [the online discussion] was a lot of work, but it was for a purpose."

Although the participation of the learning community was quite active some members participated sparingly. Probably, for those members, the protocol only extrinsically motivated them to fulfill the requirement of the class. Bob, Debra, and Chloe posted 1-2 messages per week. There were some common characteristics among their postings. First, they posted their initial thoughts relatively close to the deadline, sometimes minutes before the deadline. In our forum, very few people posted after the deadline. If members posted their initial thoughts close to the deadline, they usually would get very little feedback. Late postings could mean that they did not value peer feedback, did not like the online discussion, or they were very busy and did not have much time for online discussion. Indeed, Bob and Debra were not very active during inclass discussion, neither.

Second, those three members did not engage actively in the online discussion. When they responded, the messages were usually short and merely a form of approval to their peers. For example, Debra commented on Chloe's initial posting on week 6 with only one sentence, "The chef and customer quote is really perfect to use here!" One difference among the three of them was the number of messages they read. Bob read very few messages, around 3-8 per week. It was not a surprise that he could not make too much contribution to the community. However, Debra and Chloe read a lot more messages than Bob did. Debra and Chloe might not be motivated to contribute to the forum, but they were motivated to consume the knowledge shared by the community. However, we found that the number of messages that Debra and Chloe read decreased over the semester, probably related to other motivational factors. For instance, health reasons prevented Chloe to put in a lot of effort in the learning community.

Finally, some members found that the protocol did not work well for them. Janet said, "I posted on Friday, but nobody posted back until Saturday... I didn't respond to questions that came in really late." She suggested moving the deadline for the initial posting to Wednesday, so that the peers would have three days to interact. Ella also had similar experience regarding the deadline. She said, "I tried to use Sunday as my Sabbath ... but, everybody posted on Sunday, between 10:00pm and mid-night. It is not the ideal time."

All in all, we found that the protocol of the learning community provided guidelines to members, and the structure of the online environment engaged members in the learning activities. This finding is consistent with previous studies regarding the structure of classrooms and students' engagement (Ames, 1992; Jang, Reeve, \& Deci, 2010). We found that extrinsic motivation could trigger the formation of the community. However, a good protocol was also needed to sustain the engagement in an asynchronous 
virtual learning community. In our study, the late deadline affected some members negatively because their personal schedule did not allow them to interact with many students who posted late.

\subsubsection{Small Group Discussion}

To sustain members' motivation to participate in the online discussion, the instructor divided the class into three groups to reduce members' load in reading and responding in the learning community. In general, the characteristics of the group members were similar among groups. Each group had 5-6 members including 1-2 international members who were relatively new to the country, at least one person with teaching experience, and at least one person with industry or corporate working experience.

Although the online community was vibrant, the grouping did not work as expected. We noted various issues. The instructor intended to reduce the students' workload by asking them to interact with the members within their own group, but members chose to read and post across all three groups. It could be that members' different schedules and different interests prevented them from collaborating efficiently. Janet said that she often found few people in her assigned group to interact with when she posted her responses two or three days before the deadline. As a result, she was forced to join another group's discussion where more people were participating. Anna preferred real-time discussion. However, she usually went to bed early and posted early. She found that the other members were not logged on when she posted. Therefore, she could not receive immediate feedback, which made her feel disconnected with the community. The members not only joined a discussion according to their schedules, but also joined the discussions that were interesting to them. During the interviews, many members said that they paid close attention to pick and choose relevant discussions to read and response. Hence, some members, like Ella, who tried to stay in the group, felt frustrated when the other group members stopped contributing in her group.

\subsubsection{The Role of Guiding Questions}

Besides providing structure to the discussion forum, the instructor of the class also provided guiding questions to the class to facilitate their online discussion. Guiding questions could be important in a virtual learning community by (1) starting the conversation in the community, and (2) providing focus for the members during online discussion to build their epistemic frames of instructional design.

First, guiding questions helped the members to start the conversation. Members were required to read a few chapters from three different textbooks every week; without the guiding questions, members would find it difficult to start discussion. Eva said, "I think without those, there is nothing to write. I think you really have to have some form of questions to address." In addition to getting the members to start discussing in the forum, the guiding questions also helped the members to focus on the key issues of the week. Janet said, "That's so much in those chapters. If they're not guided, everybody would have started picking up odd things." The guiding questions allowed the community to share their skills, knowledge, and values around some focused topics every week. Consequently, members could build their understanding of instructional design and transfer the skills to the project they worked on throughout the semester.

Although members in the class valued the usefulness of the guiding questions, some guiding questions were more useful than others in generating volume of and depth 
in discussion. We observed that the number of messages spiked at week 10; the increase of the number of postings might be due to the type of the guiding questions for that week. The guiding questions of this week required members to synthesize what they had learned regarding learning theories, instructional theories, and instructional models. This kind of questions fostered members' creativity to conceptualize very ill-structured knowledge with metaphors and analogies. For instance, Ian used the metaphor of a pot of flower to show the relationships among learning theories and instructional models. His posting raised a lot of interest and generated a lot of discussions in the learning community. Some members asked him to explain how the theories and instructional models could be related to this metaphor, while the other members suggested other interpretations of his metaphor.

We found that the task of discussion that assigned members to different roles also generated interesting discussions that could lead to development of epistemic frame. The instructor asked experienced members to share their understanding of the roles and tasks of instructional designers while encouraging less experienced members to ask the experienced members questions. The members in the learning community were given clear roles, either as experts to share their experiences in their own fields or as novices to learn about the field. In such scenarios, a lot of members asked questions and shared their experiences, which not only allowed the novices to learn the practice in the industry and also allowed the "expert" members to reflect on their identity and values of the field.

\subsection{Question 3. What are the dynamics of group interaction that support collective knowledge construction process in ID learning community?}

In our learning community, members were not assigned any leadership roles. However, interestingly, we observed an important dynamic of the group interaction that significantly supported collective knowledge construction process. Leaders emerged in this learning community. A few individuals were perceived as leaders by the rest of the members through their consistently active participation, their knowledge and expertise, and their actions that won them the trust as a leader. In the following sections, we elaborate on these behaviors demonstrated by those leaders. In addition, we describe how their leadership behaviors influenced reflective participation and knowledge constructions in the community.

\subsubsection{Leading by Consistent Active Participation}

Active participation involved consistently posting and reading more messages in the discussion forum and providing critical and constructive feedback to other members that were aimed at improving other members' learning. Lily, Janet, and Luke were some of the most active members in the forum, who emerged as leaders in the learning community due to their active participation. They not only contributed about $1 / 3$ of the postings in the forum, but also played active roles in leading the discussions, such as initiating discussions by sharing their own experiences, providing constructive opinions to their peers, asking clarification questions, and pointing out potential errors. In addition, they also seemed to read more messages than other members did. Although they were required to only interact with the groups that they were assigned to, these emerging leaders read more messages than required by reading messages from all three groups. From the discussion logs, we found that two of the emerging leaders, Lily and Luke, read all the messages almost every week. In addition, they also provided constructive feedback to their peers. Luke said, "I tried to give feedback that would be useful to others". Lily 
tried to help out her peers by providing critical responses. Some of those critical responses included "I honestly don't think you should test psychomotor skills with a multiple choice test", "I don't think you understood this correctly (SR pg111) [according to our textbook page 111]", "your objective should specify the information to be learned and how the learner will demonstrate their understanding of the information".

\subsubsection{Leading by Knowledge and Expertise}

Individual members' knowledge and expertise that were evident in their high quality work was another characteristic that helped some members emerged as leaders in the learning community. For instance, many members realized the quality of work done by Luke and Joseph. As a result, many members chose to read their projects, and used them as guides in developing theirs. Ella understood APA writing style well. Because many of our members were new to APA style, they would read Ella's project to model the APA writing style. In an interview with Janet to discuss about how members' modeled each other work, she said, "I am sure there were plenty of people that were excellent at what they did ...Luke's would be long, Joseph's would be short, Lily's would be well written, Ella wrote APA [well]". Because the learning community was made up of members who brought with themselves different set of knowledge, skills, and expertise, the members of the learning community perceived those possessing the desired expertise as role models to guide their tasks.

\subsubsection{Leading by Trust and Care}

Another important characteristic of emergent leaders in the learning community was their behaviors, which showed that they cared about their fellow members. The caring behaviors of these individuals then contributed to a trusting community. For instance, during the interviews, both Lily and Janet mentioned that they got very little feedback from the discussion forum. However, both of them devoted considerable amount of time and effort in the learning community because they wanted to help their fellow members in the class. In multiple occasions, Zoe referred to Lily and Janet as her "intellectual moms". In the interview, Zoe said, "Lily helped me to write; she helped me to clarify... Also, Janet guided me how to write objectives". Zoe felt very comfortable to ask Lily and Janet question because she knew that they would answer her questions patiently.

\subsubsection{Leading by Building a Collaborative Learning Community}

The emergent leaders also exhibited behaviors that encouraged the team members to direct their attention to important collaborative learning opportunities. As described earlier, Ian posted a very interesting diagram to represent his idea about different ID theories and concepts. Fascinated by Ian's diagram, Lily posted messages to all the three groups to draw the peers' attention to Ian's work. As a result, many people replied to Ian's thread and created one of the most heated threaded discussions in the forum. This type of community maintenance behavior led to a great opportunity for the whole group, which would otherwise be missed if it were not for Lily's emergent leadership.

\section{Discussion}

The three research questions investigated in this study led to some very interesting findings that helped us to understand the interrelationships of different components in a 
virtual learning community: (1) characteristics of community members (individual and group), (2) members' interaction processes, (3) members' participation and leadership, (4) scaffolding mechanisms and strategies, and (5) the outcomes of a reflective ID learning community. Figure 1 presents a conceptual model that is built on the findings, which illustrates the interrelationships among different components. More specifically, Figure 1 attempts to illustrate how a reflective ID learning community was developed and scaffolded, what individual characteristics contributed to the group characteristics, how group characteristics facilitated knowledge construction and building, and how emerging leadership played a role in shaping the community.

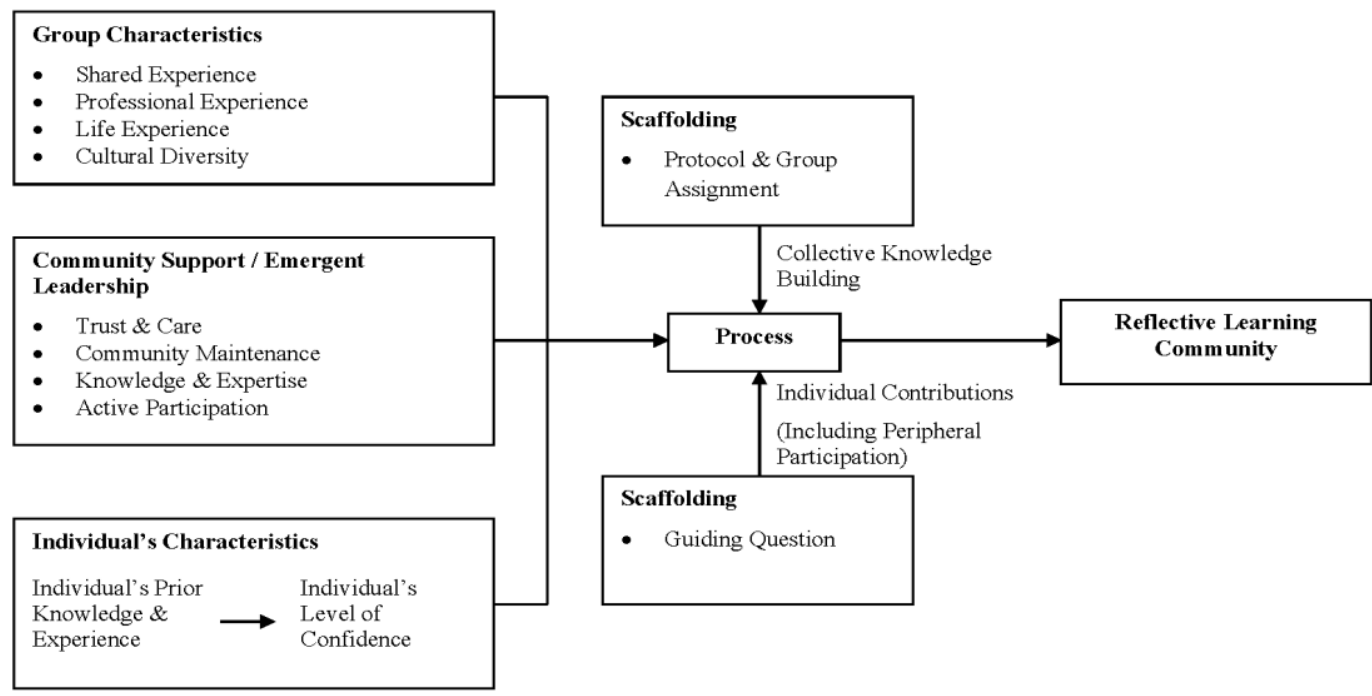

Figure 1. A conceptual model illustrating the interrelationships among different components of a virtual learning community: (1) characteristics of community members (individual and group), (2) members' interaction processes, (3) members' participation and leadership, (4) scaffolding mechanisms and strategies, and (5) the outcome of a reflective ID learning community.

We found that the individual prior knowledge and experience contributed to the collective knowledge of the community, which in a way influenced social interactions and knowledge construction processes of the community. It is particularly worth noting how international students used different techniques to participate in the community activities and to overcome their language and cultural barriers, gradually moving away from peripheral participation towards centric participation, and how the other community members provided support to these individuals as they were trying to adapt to the community culture. As a group, this community shared a pool of knowledge and experience, which not only supported individual members with different knowledge and confidence levels, but also facilitated the peer interaction processes and nurtured the development of the community.

At the same time, the discussion protocols, group assignments (involving member composition, individual personality, and individual schedules), and guiding questions all 
served as supporting mechanisms to scaffold the knowledge construction process of the community. It not only deepened individuals' understanding and developed their expertise of ID, but also promoted the epistemic frames of a reflective ID learning community.

Leadership emerged as a theme that had a positive influence on creating a positive environment and nurturing a motivating culture for community members with their active participation, knowledge and expertise, caring and trust, as well as supporting, facilitating, modeling, and management.

\section{Implications for Instructional Design}

The results of this paper highlight a number of implications for when designing a virtual learning community. First, consistent with the results of prior studies, our results suggested the use of students' prior knowledge to scaffold students' interaction and community activities (Azevedo, Cromley \& Seibert, 2004; Ge \& Hardré, 2010). In particular, our results highlight one type of prior knowledge and experience that is relevant to the building of virtual learning community, that is, members' knowledge regarding computer-mediated communication, and their perception towards the communication media. We suggest that teachers, online instructors, and instructional designers should pay attention to those students who are not familiar with computermediated learning. Once they feel comfortable to use technology as a tool to participate in the community activity, we should encourage them to use the tool to build their knowledge with other members (Scardamalia \& Bereiter, 1994).

The international students were another asset for this learning community. On one hand, they enriched the community with diverse culture they have brought with them. On the other hand, the language and cultural barriers prevented them from participating in the community actively and effectively, which might have impeded the development of the whole community. This issue presents a unique challenge to online instructors and instructional designers. It urges us to develop effective strategies to scaffold this particular group of members and enculturate them into the learning community. Our results suggest that a vibrant learning community is vitally important in providing support to international students. One way to mitigate the language issues of international students and encourage their participation is to encourage multiple forms of representation, such as using visual representations to facilitate their participation. Alternative forms of representation not only allow members to communicate with each other when they do not feel comfortable to verbally express themselves but also stimulate their creativity in building knowledge.

Our results agree with the prior research that external factors, such as reward, the discussion topics, and students' availability of time, may affect students' contribution to learning communities (Cheung, Hew, \& Ng, 2008). We found that rewards, such as giving course credits for participation, could lead students to participation, but it might not be enough to sustain active reflection of the whole community. In our study, a few students participated in the community to meet the class' minimum requirements. Although those students provided their perspectives to the discussion topics, they did not give meaningful responses to their peers, and hence the members in the community could not engage in deeper reflective interactions. Nevertheless, many students in our community actively looked for interesting topics that they could learn from and contribute to the community. They were intrinsically motivated to learn and participate, and their contributions allowed the whole community to deeply reflect on the knowledge 
domain. Therefore, it is important for instructors to design the learning environment so that students' extrinsic motivation to participate can be transformed into intrinsic motivation to learn and to give.

\section{Implications for Future Research}

Although our study provides some interesting insights regarding the development of a virtual learning community, there are remaining questions regarding the scaffolding of virtual learning communities. First, how much structure should we put in a virtual learning community? The nature of asynchronous discussion allows members to participate in the community at their own time. However, a good learning community requires at least a number of members to participate within a period of time so that they can have meaningful interactions. As a result, there is a tension between flexibility and structure that affect meaningful interactions. This finding is consistent with prior research that teachers should provide proper structures to the students in an online learning community (Sun, 2011). We need to further investigate the issue on how to strike a balance between flexibility and structure to maximize participation.

Our study provided evidence that guiding questions were helpful to focus members' attention on important concepts and issues in their reading assignments and facilitate their understanding of the issues under discussion. This finding was consistent with the previous research, which shows that different types of question prompts are a successful scaffolding technique in the contexts of ill-structured problem-solving (Ge \& Land, 2003) and complex science topics (Azevedo, Cromley, \& Seibert, 2004). However, this study further revealed the function of question prompts by indicating that certain types of guiding questions were more effective than others regarding facilitating meaningful discussion. Future research is needed to understand in what conditions and in what ways different types of guiding questions affect knowledge construction and knowledge building in a learning community.

Another important question for future research is when guiding questions should fade out. Although providing guiding questions can be an effective strategy to scaffold online interactions, we hope that our students will eventually be able to participate in the social interactions effectively without being scaffolded (Pea, 2004). In our virtual learning environment, the instructor provided guiding questions throughout the semester. In the future, it is necessary to examine when and how to fade the guiding questions as a learning community develops and grows over time.

Another interesting finding was the emergent roles of shared leadership in the virtual learning team. While this virtual learning team was leaderless in the sense that no leader or follower roles were imposed on the team members, we found that a few of the team members did emerge as leaders of the community due to their consistently noteworthy behaviors. However, the leadership was shared, meaning that any individual who displayed one or more of these behaviors for a period of time was perceived as a leader during that period of time. Hence, several different individual emerged as leaders at different times and their leadership recognizably contributed to the success of the relevant team activities during a particular time period. We can relate this study well with the similar findings found in other disciplines, which suggests that one of the factors that separates successful and unsuccessful self-managing virtual teams is the emergence of leadership (see, for instance, Eseryel, 2010; Yoo \& Alavi, 2004). Shared leadership is not studied thoroughly in the context of virtual learning communities. However, based on the findings of our study, we contend that shared leadership has an important role in 
supporting learning communities that truly collaborate. Hence, it is important to conduct further studies to examine how to cultivate shared leadership behaviors to support effective virtual learning communities, which embody a "culture of learning in which everyone is involved in a collective effort of understanding" (Bielaczyc \& Collins, 1999, p. 271).

\section{Conclusion}

Studies of online discussion have been conducted to understand the factors contributing to successful online discussions (e.g. Cheung, Hew, \& Ng, 2008; Denner, 2005), and different ways to scaffolds online discussions (e.g. De Wever, Schellens, van Keer, \& Valcke, 2008; Jeong \& Joung, 2007). Those studies assume that students participate actively in the learning environment to share information and construct knowledge. However, little empirical evidence was found to support this assumption. Using the lens of community of practice (Lave \& Wenger, 1991), in this study, we were able to observe how the members of our learning community developed their epistemic frames through their active engagement in the community. We do not attempt to generalize the results to other contexts; instead, through the observations of the learning community, we were able to explore how students' prior knowledge affected their engagement and learning, how a special group of members enculturated themselves in the community, how different strategies were implemented, and how leadership emerged in the community. The findings of this study further confirmed the needs and benefits of a learning community in developing the expertise of instructional design. The community, which constituted of individuals with different prior knowledge and background, provided a shared repertoire of knowledge and rich resources that could be drawn to scaffold the expertise development.

\section{References}

1. Ames, C. (1992). Classrooms: Goals, structures, and student motivation. Journal of Educational Psychology, 84(3), 261-271. doi: 10.1037/0022-0663.84.3.261

2. Azevedo, R., Cromley, J.G., \& Seibert, D. (2004). Does adaptive scaffolding facilitate students' ability to regulate their learning with hypermedia? Contemporary Educational Psychology, 29(3), 344-370. doi: 10.1016/j.cedpsych.2003.09.002

3. Barab, S.A., \& Duffy, T.M. (2000). From Practice Fields to Communities of Practice. In D. H. Jonassen \& S. M. Land (Eds.), Theoretical Foundations of Learning Environments (pp. 25-56). Mahwah, NJ: Lawrence Erlbaum Associates.

4. Bielaczyc, K., \& Collins, A. (1999). Learning communities in classrooms: A reconceptualization of educational practices. In C. M. Reigeluth (Ed.), Instructional-design theories and models: A new paradigm of instructional theory (pp. 269-292). New Jersey: Lawrence Erlbaum.

5. Brown, A.L., \& Campione, J.C. (1994). Guided discovery in a community of learners. In K. McGilly (Ed.), Classroom lessons: Integrating cognitive theory and classroom practice (pp. 229-270). Cambridge, MA: MIT Press.

6. Cheung, W.S., Hew, K.F., \& Ng, C.S.L. (2008). Toward an understanding of why students contribute in asynchronous online discussions. Journal of Educational Computing Research, 38(1), 29-50. doi: 10.2190/EC.38.1.b 
7. Creswell, J.W. (2007). Qualitative inquiry and research design: choosing among five approaches. Thousand Oaks, CA: SAGE.

8. De Wever, B., Schellens, T., Van Keer, H., \& Valcke, M. (2008). Structuring Asynchronous Discussion Groups by Introducing Roles: Do Students Act in Line With Assigned Roles? Small Group Research, 39(6), 770-794. doi: $10.1177 / 1046496408323227$

9. Dennen, V.P. (2005). From message posting to learning dialogues: Factors affecting learner participation in asynchronous discussion. Distance Education, 26(1), 127-148. doi: 10.1080/01587910500081376

10. Eseryel, U.Y. (2010). Leadership behaviors and perception in self-managing virtual teams. Ph.D. Doctoral Dissertation, Syracuse University, Syracuse, NY.

11. Feltovich, P.J., Spiro, R.J., Coulson, R.L., \& Feltovich, J. (1996). Collaboration within and among minds: Mastering complexity, individually and in groups. In T. Koschmann (Ed.), CSCL: Theory and Practice of An Emerging Paradigm (pp. 2544). Mahwah, New Jersey: Lawrence Erlbaum Associates.

12. Ge, X., \& Hardré, P. (2010). Self-processes and learning environment as influences in the development of expertise in instructional design. Learning Environments Research, 13(1), 23-41. doi: 10.1007/s10984-009-9064-9

13. Ge, X., \& Land, S. (2003). Scaffolding students' problem-solving processes in an ill-structured task using question prompts and peer interactions. Educational Technology Research and Development, 51(1), 21-38. doi: 10.1007/BF02504515

14. Goel, V., \& Pirolli, P. (1989). Design within information-processing theory: The design problem space. AI Magazine 10(1): 19-36.

15. Greeno, J.G., Korpi, M.K., Jackson, D.N., Michalchik, V.S. (1990). Ill-structured problem solving in instructional design (pp. 939 - 946). Proceedings of the Annual Conference of the Cognitive Science Society. Hillsdale, NJ, Erlbaum.

16. Jang, H., Reeve, J., \& Deci, E.L. (2010). Engaging students in learning activities: It is not autonomy support or structure but autonomy support and structure. Journal of Educational Psychology, 102(3), 588-600. doi: 10.1037/a0019682

17. Jeong, A., \& Joung, S. (2007). Scaffolding collaborative argumentation in asynchronous discussions with message constraints and message labels. Computers \& Education, 48(3), 427-445. doi: DOI: 10.1016/j.compedu.2005.02.002

18. Lave, J., \& Wenger, E. (1991). Situated learning: Legitimate peripheral participation. New York, NY: Cambridge University Press.

19. Pea, R.D. (2004). The social and technological dimensions of scaffolding and related theoretical concepts for learning, education, and human activity. Journal of the Learning Sciences, 13(3), 423-451. doi: 10.1207/s15327809j1s1303_6

20. Perez, R.S., Johnson, J.F., \& Emery, C.D. (1995). Instructional design expertise: A cognitive model of design. Instructional Science, 23, 321-349.

21. Renninger, K.A., \& Shumar, W. (2002). Building virtual communities: Learning and Change in Cyberspace. New York, NY: Cambridge University Press.

22. Scardamalia, M., \& Bereiter, C. (1994). Computer Support for KnowledgeBuilding Communities. The Journal of the Learning Sciences, 3(3), 265-283. doi: 10.1207/s15327809jls0303_3

23. Schön, D.A. (1987). Educating the Reflective Practitioner: Toward a New Design for Teaching and Learning in the Professions. San Francisco: Jossey-Bass. 
24. Shaffer, D.W. (2006). Epistemic frames for epistemic games. Computers and Education, 46(13), 223-234.

25. Shank, G.D. (2002). Qualitative Research: A personal skills approach. Upper Saddle River, New Jersey: Merrill and Prentice Hall.

26. Spiro, R.J., Coulson, R.L., Feltovich, P.J., \& Anderson, D.K. (1988). Cognitive flexibility theory: Advanced knowledge acquisition in ill-structured domains. Champaign, IL: University of Illinois, Center for the Study of Reading.

27. Sun, S.Y.H. (2011). Online language teaching: the pedagogical challenges. Knowledge Management \& E-Learning: An International Journal, 3(3), 428-447.

28. Thomas, M.J.W. (2002). Learning within incoherent structures: the space of online discussion forums. Journal of Computer Assisted Learning, 18(3), 351-366. doi: 10.1046/j.0266-4909.2002.03800.x

29. Vygotsky, L.S. (1978). Mind in society: The development of higher psychological processes. Cambridge MA: Harvard University Press.

30. Webb, N.M., \& Palincsar, A.S. (1996). Group process in the classroom. In D. C. Berliner \& R. C. Calfee (Eds.), Handbook of educational psychology (pp. 841-876). New York, NY: MacMillan.

31. Wenger, E. (1997). Communities of practice. Learning, Meaning, and Identity. New York, NY: Cambridge University Press.

32. Wise, A., Speer, J., Hsiao, Y.-T., \& Marbouti, F. (2011). Factors contributing to learners' online listening behaviors in online and blended courses. Paper presented at the 9th International Computer-Supported Collaborative Learning Conference, Hong Kong, China.

33. Xie, K., \& Ke, F. (2009). How does students' motivation relate to peer-moderated online interactions? Paper presented at the 8th International conference on Computer-Supported Collaborative Learning, Rhodes, Greece.

34. Yin, R.K. (2008). Case study research: Design and methods (4th ed.). Thousand Oaks, CA: Sage Publication.

35. Yoo, Y., \& Alavi, M. (2004). Emergent leadership in virtual teams: what do emergent leaders do? Information and Organization, 14(1), 27-58. doi: 10.1016/j.infoandorg.2003.11.001 